\title{
AUTOMATION FOR IMPROVED SAFETY IN ROADSIDE CONSTRUCTION
}

\author{
*S. Bergquist ${ }^{1,2}$, C. Grante ${ }^{1}$, J. Fredriksson ${ }^{2}$ and J. Sjöberg ${ }^{2}$ \\ ${ }^{1}$ Volvo Group Trucks Technology \\ Advanced Technology \& Research \\ Göteborg, Sweden \\ ${ }^{2}$ Chalmers University of Technology \\ Department of Signals and Systems \\ Göteborg, Sweden \\ (*Corresponding author: steber@chalmers.se)
}




\title{
AUTOMATION FOR IMPROVED SAFETY IN ROADSIDE CONSTRUCTION
}

\begin{abstract}
In this paper, it is investigated how different types of automation would affect the safety for workers in asphalt paving. The risk for the workers on road construction sites is consistently high in comparison to the average risk of the working population. Automation has been suggested as an alternative for improving the safety in roadside construction assuming that removing workers will inherently eliminate the risk of them being injured. In this paper, the potential for improving the safety using automation is analyzed in detail. By investigating accident statistics and understanding the type of accidents that appear, several different automated functions for increased safety are proposed and described. Based on available statistics, it is possible to estimate the safety benefit, as the reduction in fatalities, for several of the proposed functions. The highest safety benefit would be achieved by automating the road traffic driving through the work zones. This has the potential of reducing the total number of road worker fatalities with over $30 \%$. In addition, it would decrease the number of road traffic accidents in work zones. Automation of construction machinery and dump-trucks also has the potential to increase the safety.
\end{abstract}

\section{KEYWORDS}

Automation, safety, active-safety, roadside construction, asphalt paving, accident analysis.

\section{INTRODUCTION}

The risk for workers on the road is consistently high in comparison to the risk most other people are exposed to when at work (Laborers' Health and Safety Fund of North America, 1998). In a study from the UK Highways Agency published in 2006, almost $20 \%$ of the responding road workers had been injured due to a passing vehicle at some point of their career (MVA, 2006). It was further reported that $54 \%$ had experienced a near miss. Apart from the obvious risk for physical injury, the work on the road also has negative psychological effects on the workers. In 2011, the union of road workers in Sweden published a report based on interviews with one thousand road workers (SEKO, 2011). The report showed that $72 \%$ of the workers are occasionally worried about the safety when working on the road. Furthermore, $88 \%$ of the respondents did not think the road users showed sufficient respect for the construction workers.

Automation has been suggested as a possible alternative on how to improve the safety in roadside construction (Haas \& Kim, 2002; Skibniewski \& Hendrickson, 1990). The basic idea is that removing the operators from dangerous areas eliminates the risk of them being injured. It is further known from traffic research that about $90 \%$ of the accidents are due to the human factor. Hence, by automation, the corresponding accidents would be avoided. Removing the operator implies that the entire task needs to be handled automatically. This can be separated from emergency based automation where the function takes over control only in specific situations. This type of functions is often referred to as active safety functions.

The aim of this research is to investigate how different types of automation can increase the safety in roadside construction. The main focus of the study is accidents in asphalt paving with risk for severe injuries or fatalities. Furthermore, the scoop includes only the safety of the workers and not the road traffic (the traffic passing the construction site which is not part of the construction work). 


\section{OUTLINE OF THE STUDY}

To give a general understanding of asphalt paving and aid the comprehension of safety issues the first part of the paper, description of the road construction site, describes an asphalt paving site. The description is mainly based on participant observation studies carried out by one observer during 2011 and 2012. In total, four construction sites in Sweden and one in US were included in the study. The sites were visited one to three times each depending on complexity and job duration. The sites where chosen to cover different types of paving such as parking lots, rural roads and motor ways. The site in US was included to compare Swedish (European) paving with American.

In the second part, accident analysis, an analysis of the safety is presented based on a qualitative and quantitative study. The qualitative study is performed to get a deeper understanding of accident types in asphalt paving and to be able to relate quantitative data for general road works to asphalt paving. The qualitative study included eight deep interviews with six subjects from Sweden and two from US. The interviews were semi-structured and led by one researcher. The study further included three focus group discussions, two in Sweden and one in US including in total 14 subjects. The focus group discussions were semi-structured and lead by one researcher. The total sample size was chosen to include a broad view of expertise within the area of asphalt paving. The sample included road workers, representatives from a machine manufacturer, a retail organization, road work contractors and the road administration in Sweden. The quantitative study is mainly based on earlier published data from US and complemented with unpublished accident data from a Swedish insurance company (AFA Insurance) and incident reports from some of the major Swedish road work contractors (PEAB, SKANSKA, SVEVIA). The AFA Insurance data included in total 47 accidents reported from 2005 to June 2012 while the road contractor data included 364 relevant incident and accident reports from 2010 to 2012. In both cases, the received data was in the form of accident and incident descriptions that had to be individually analyzed and clustered.

In the third part, automation and safety, automation concepts to increase the safety are described and potential safety benefits are evaluated. The safety benefit estimations are based on the quantitative data from the accident analysis.

\section{DESCRIPTION OF THE ROAD CONSTRUCTION SITE}

The aim of the asphalt paving zone is to create or replace a layer of asphalt on a new or existing road. The description is based on participant observation studies described in outline of the study. A sketch of the construction site is shown in Figure 1. The work is performed in three different zones, the paving zone, the delivery zone and the compaction zone. Together they make up the construction zone. In many cases, road traffic is passing by close in a traffic zone.

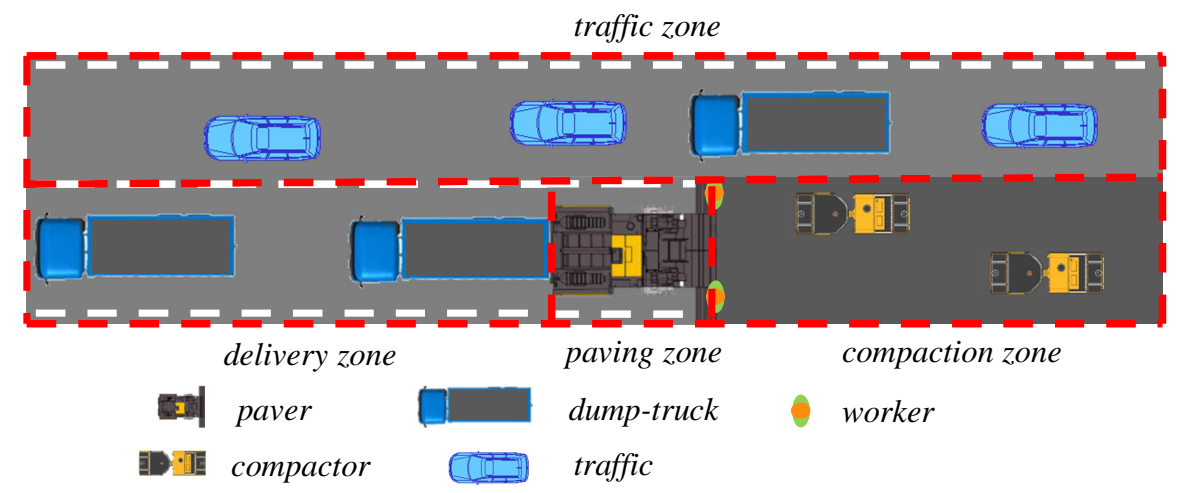

Figure 1 - Overall view of asphalt paving 
In the delivery zone, the trucks from the asphalt plant wait in line to deliver the asphalt. When its turn comes, the truck reverses towards and docks to the paver in the paving zone. The paver then pushes the truck while retrieving the asphalt in to its material hopper. When the truck is empty, it leaves the position and allows the next truck to dock to the paver. The material that enters the hopper is transported through the paver to the screed which is pulled behind the machine. After the screed, an even layer of asphalt is produced over the roadway. To achieve high quality, the material needs to be compressed. In the compaction zone, one or more compactors, follows the paver and operates in a predefined back and forth pattern to achieve the desired density. In the traffic zone, road traffic passes the construction zone.

There are a number of people involved in the process on the construction site. Each truck has a driver and each compactor has an operator. The paver normally has three operators, one on top of the machine while two screed operators travels on the screed or walks behind the machine. Apart from the machine operators there are often several workers that perform manual tasks on the ground.

When paving on existing roads, it is often the case that the road needs to stay open for traffic. Therefore, road traffic are often passing by very close. Especially, the screed operator on the traffic side of the paver is always positioned in a potentially dangerous spot close to the passing cars.

\section{ACCIDENT ANALYSIS}

Safety in regard to work zones includes both the safety of the passing traffic and the safety of the workers. The road traffic safety aspect has been investigated by several researchers. In general, the publications conclude that there is an increased accident risk on a road stretch with ongoing road work (Friberg, 2007; Tighe \& McCabe, 2006). The most common accident type is collision, either with a preceding vehicle which stopped for the construction zone (rear-end collision) or in to fixed objects in the work zone (Elghamrawy, 2011; Mahoney et al., 2006). Excessive speed has been pointed out as one common reason for traffic accidents in road works (Friberg, 2007; Tighe \& McCabe, 2006).

\section{Worker Safety}

To get a detailed picture of the accident situation in asphalt paving and an understanding why accidents occur, a qualitative study was performed as described in outline of the study. The findings from the qualitative study are then compared to available data about accidents in roadside construction.

\section{Qualitative study}

The subjects give a unified view of the risks that exist for the workers on the road. Therefore, the material can be analyzed as a whole to give one description of the safety problem in asphalt paving.

When working on the road, there are threats from both outside the construction zone as well as from within the zone. In asphalt paving, the road traffic is often passing close to the workers and at the same time, machinery and trucks are operating within the construction zone. This can lead to dangerous situations and all subjects can recall serious incidents or accidents that they or someone they know have been involved in.

When focusing on severe accidents, it is obvious from the study that the road traffic is involved in most accidents. The vehicles collide with different parts and actors in the construction zone. Most often it is items such as signposts or barriers designed for collision, but on occasions, it is machines or workers. In comparison to the operators in the machines, the workers on the ground are unprotected. The consequences of a vehicle striking a worker are therefore normally severe. In most cases when a worker is struck, the vehicle intrudes into the construction zone where the accidents occur. However, in asphalt paving there is not always a clear line between the zones where the workers should be and where the road traffic should be. The subjects feel that the respect for construction workers is low among the road traffic population and 
that people often drive with high speeds and close to the workers. Trucks and buses are over-represented in safety critical situations. This is partly explained by the size and that they need more space, and that they often have tight schedules that need to be kept which can result in high speed.

Within the work zone, the compactors are pointed out as the greatest threat for the workers. There is an apparent risk to be "struck by" a compactor when working in the compaction zone. The compactors operate back and forth in the compaction zone and are driven towards the workers many times per day. In a moment of low attention there is risk for striking either a worker or the paver. The consequences can be severe. There is also a risk of being "struck by" the asphalt dump-trucks in the delivery zone. The trucks reverse towards the paver and a worker could be struck or pinched between the vehicle and paver. However, "struck by" truck accidents are not as common as "struck by" compactor accidents. This can be explained by the fact that there are normally less people in the delivery zone than in the compaction zone. In the compaction zone, there are workers all the time. In the delivery zone, there are only workers on occasions and at those times this should be communicated to the truck drivers.

Apart from "struck by" accidents, there are also other types of accidents that can have severe consequences, for example, roll-over accidents. However, this type of accident is uncommon in paving since the ground is flat and well-prepared. More frequent accidents are trip and falls that occur either when entering/exiting the machine or on the ground. The consequences here are generally less severe.

The conclusion of the qualitative study is that the severe accidents are "struck by" accidents and in order of most common:

1. Worker "struck by" a road traffic vehicle. The majority of the accidents occur when vehicles intrude into the construction zone. Trucks and buses are over-represented.

2. Worker "struck by" a compactor in the compaction zone.

3. Worker "struck by" a truck in the delivery zone.

\section{Quantitative study}

Two investigations based on fatal accidents at road construction sites in the US using data from the Bureau of Labor Statistics Census of Fatal Occupational Injuries (CFOI) have been conducted (Pegula, 2004, 2010). They include the years 1995 to 2002 and a total of 844 fatal accidents and the years 2003 to 2007 with 639 fatal accidents. The distribution of the fatalities is seen in Figure 2a. For both periods, the most common cause of death was "struck by vehicle or mobile equipment" (includes machines) which included $55 \%$ of the fatalities. This supports the conclusion that "struck by" accidents are common in roadside construction and also specifically in asphalt paving. The second largest cause was "highway or non-highway incident" which includes all accidents when the victim was operating a machine or vehicle and is therefore quite wide. For example, this category also includes fatalities during transportation which did not occur at the actual construction site. The remaining categories are small and it can be established that, apart from "struck by" accidents, there are a wide spread in the causes for fatal accidents.

The distribution between vehicles and machines is shown in Figure $2 b$. It shows that $60 \%$ of the "struck by" accidents were due to the road traffic. This is in line with the qualitative study but a greater majority was expected. A possible explanation for this can be that the CFOI data are for all road construction sites. In asphalt paving, the dump-trucks and machinery have clearly specified tasks and zones which could lead to fewer accidents. Data specific for asphalt paving were received from AFA Insurance as described in outline of the study. The data contained 9 "struck by" accidents. These very few data indicate that there is a rather even relationship between road traffic vehicles (4) and construction equipment (5) accidents. An analysis of (unpublished) incident data received from Swedish road work contractors described in outline of the study showed that $85 \%$ of those reports involved a vehicle from the road traffic. It could be the case that the many incidents with cars, trucks and buses may lead to the conclusion that there is the same relationship between the categories when looking at severe accidents. However, this is not necessarily true. It is possible that road traffic incidents are more often perceived as dangerous compared to, for example, compactor incidents since the speeds are higher and the driver unknown. 
The CFOI data showed that trucks are more common than cars in fatal accidents. In the data from Swedish road contractors, $33 \%$ of the road traffic situations involved trucks or buses. Given the share of trucks and buses in the traffic population, this supports the conclusion from the qualitative study that trucks and buses are over-represented in incidents and accidents. Moreover, the great majority of the incidents included vehicles intruding the construction zone. This supports the conclusion that most accidents are within the construction zone which has also been shown in another study of CFOI data (Pratt et al., 2001).

The CFOI data shows that $2.6 \%$ of the "struck by" fatalities are due to pavers and compactors. Most of these accidents can be expected to be due to compactors since the pavers normally move about ten meters/minute. The data from AFA Insurance support this since there are three compactor accidents and only one with a paver. According to CFOI data, $21 \%$ of the fatalities are due to dump-trucks. These figures are not consistent with the conclusion of the qualitative study where compactor accidents were more common than dump-truck accidents. However, the CFOI data are for all road construction. Asphalt paving can be expected to have fewer truck accidents since the delivery zone is very well defined and there are normally no people within the zone. The conclusion from the qualitative study is supported by the data from AFA insurance where four accidents with pavers/compactors are included compared to one dumptruck accident. It can therefore be expected that the number of "struck by" dump-truck accidents that occur in asphalt paving should be smaller than the number of "struck-by" paver/compactor accidents.

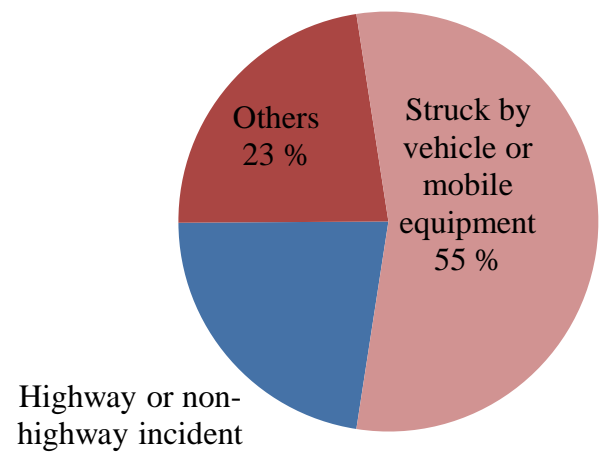
$22 \%$

Figure $2 \mathrm{a}$ - Distribution of fatalities in roadside construction

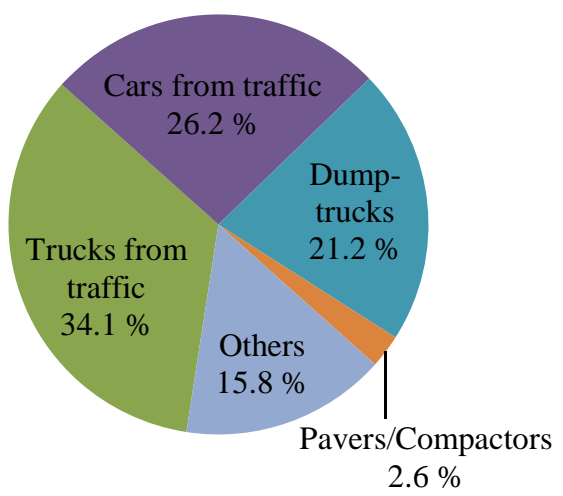

Figure $2 b$ - Distribution of fatalities within "struck by vehicle of mobile equipment"

\section{AUTOMATION AND SAFETY}

Based on the accident types in section accident analysis, the effect of different safety of automation concepts can be estimated. The analysis showed that the most frequent severe accidents are "struck by vehicle or mobile equipment". This type of accidents could be avoided by either full automation where the machine is controlled never to strike a worker, or by active safety functions which intervene if an accident is imminent. A list of possible automated functions to remove "struck by" accidents and improving the safety in road works and asphalt paving are presented in Table 1.

Table 1: Automation for increased safety

\begin{tabular}{lll}
\hline Struck by & Active safety function & Fully automated function \\
\hline Vehicle or mobile equipment & - & - Automation of manual tasks \\
Road traffic vehicle & - Emergency braking & - Automated driving through construction sites \\
Compactor & - Emergency braking & - Automated compaction \\
Dump-truck & - Emergency braking & - Automated docking to paver \\
\hline
\end{tabular}


The safety effect of the proposed functions in Table 1 is analyzed in the following paragraphs. The safety benefit is calculated as the percentage of the fatalities that could have been avoided by the specific function. For the calculations, the CFOI data (Pegula, 2004, 2010) and the distributions in Figure $2 \mathrm{a}$ and $\mathrm{b}$ are used. For example, automating the road traffic driving through construction sites could avoid workers being hit by traffic. The possible benefit is calculated as $55 \%$ ("struck by" fatalities out of all fatalities) times $60.3 \%$ ("struck by" road traffic out of all "struck by" accidents) resulting in $33.2 \%$. The estimated benefit could only be achieved with a system that could handle all accidents in the category and is therefore a maximum limit. The actual benefit will depend on the performance of the developed system. In worst case, incautious automation could actually decrease the safety by introducing new accidents. An overview of the estimated safety benefits is shown in Table 2. As can be expected, functions that cover general road works (1-3 and 7) will have a much higher safety benefit than functions developed for specific type of road works (4-6). However, the data from AFA Insurance indicate that "struck by" compactor accidents can make up as much as one third of all "struck by" accidents in asphalt paving.

Table 2: Possible reduction in total number of road construction fatalities based on the CFOI data

\begin{tabular}{lc}
\hline Function & Reduction in fatalities \\
\hline 1. Automation of manual tasks & $>55 \%$ \\
2. Automated driving through construction site & $33 \%$ \\
3. Emergency braking for road traffic & $33 \%$ \\
4. Automated compaction & $<1.4 \%$ \\
5. Emergency braking for compactors & $<1.4 \%$ \\
6. Automated docking & $<1.4 \%$ \\
7. Emergency braking for dump-trucks & $12 \%$ \\
\hline
\end{tabular}

\section{Automation of manual tasks}

Automation of manual tasks to remove the workers on the ground would have a very high safety benefit. At least all fatalities caused by "struck by" accidents (55\%) could potentially be avoided. Moreover, by removing workers from the site, the exposure to other accident types would also decrease and the safety benefit can be expected to be higher than $55 \%$. However, the wide range of tasks that are handled by the workers on the ground is very complex to automate. It would be possible to automate specific tasks to reduce the number of workers on the ground with limited safety benefits.

\section{Automated driving through construction site}

Automating cars, trucks and buses to follow the desired path would prevent them from intruding into the construction zone and striking people. In this way, the $33 \%$ "struck by" vehicle fatalities could be avoided. Additionally, a number of fatalities from other accidents where the vehicle strikes a machine or dump-truck could be avoided. Moreover, the safety for the road traffic would improve since the vehicles would be controlled not only to avoid workers but any items and machines on the construction site.

The concept of automated driving through construction site was researched in the European research project Highly Automated VEhicles for intelligent transport (HAVEit) (Schrinner et al., 2010). In the project, a function called Automated Assistance in Roadworks and Congestion (ARC) was developed and demonstrated. The function handled both longitudinal and lateral control when driving through work zones. Apart from the control of the vehicle which has been proven and partly exists in many cars already today, for example, Adaptive Cruise Control, also communication with the road works is needed. This type of communication between vehicles and infrastructure has been developed and demonstrated in several research projects, and is believed to reach the market in a near future. The possible biggest challenge for this type of system is the collaboration between many partners which would be needed. Car, truck, bus and 
construction equipment manufacturers would have to work together with road work contractors and road authorities for the system to become reality.

An alternative to fully automating the road traffic would be to only automate the speed control. By doing this, it would be possible to force the vehicles to follow the legal speed. High speed has been pointed out as a reason for many of the accidents. Moreover, accidents in lower speed have less severe consequences. Therefore, the safety benefit can be expected to be high also if only automating the speed.

\section{Emergency braking for road traffic}

Automated emergency braking for pedestrians exists in premium passenger cars already today. The safety benefits from this type of system would theoretically be avoiding $33 \%$ of all fatalities among road workers. However, the systems that exist today are developed to work in city environments and it is unclear how well they will perform when entering a more unstructured work site environment. Moreover, the systems only work in low speeds.

\section{Automated compaction}

Automating compactors has the potential to reduce the total number of fatalities with less than $1.4 \%$ as seen in Table 2. This includes the fatalities where a worker is struck by a compactor. There has been research towards automated compaction (Krishnamurthy et al., 1998). The developed function AutoPave monitored the position of the compactor and calculated the desired path and real-time guidance for the operator. Automatic control was not used but based on such an algorithm it would be possible to also take control over the speed and steering of the machine. However, there is a major challenge to introduce fully automated machines in an environment where a failure could have such extreme consequences as when operating close to road traffic.

\section{Emergency intervention for compactors}

In the same way as for automated compaction, emergency intervention for compactors would have the potential to remove less than $1.4 \%$ of the fatalities. Developing an emergency intervention function for compactors would be less complex than to automate the compaction. However, the safety benefits can be expected to be in the same region. Moreover, this type of functionality could be possible to move to other type of machinery with only minor modifications. Compared to fully automated functionality, it is significantly easier to introduce emergency based functionality on the machines.

\section{Automated docking}

The safety potential of automating dump-trucks would be removing $12 \%$ of the road work fatalities. However, the trucks are used in a wide range of different work sites and it would be hard to automate for all scenarios. Focusing the automation towards one area such as paving would dramatically reduce the safety benefits. In asphalt paving, for example, the dump-trucks are involved in less accidents than compactors. Therefore, less than $1.4 \%$ of the fatalities can be expected to be handled if focusing automation towards asphalt paving.

\section{Emergency braking for trucks}

An emergency braking system for trucks would be useful in general work areas. Therefore, the system would have the potential to remove all "struck" by dump-truck fatalities which equals $12 \%$ of all fatalities among road workers. Such a system would furthermore be easier to develop than automated docking. Already today there exist safety systems in premium trucks that can automatically brake the vehicle if a rear-end collision is imminent. In the same way as for compactors, it would be easier to deploy emergency based than fully automated functions in trucks. 


\section{CONCLUSION}

This paper shows that the most common severe accident type in asphalt paving is "struck by vehicles or mobile equipment". In most cases, $60 \%$, a worker is struck by a vehicle from the normal road traffic. Most of the accidents occur when a vehicle is intruding into the construction zone and trucks and buses are over represented. In the other "struck by" accidents, the worker is struck by either a compactor or a dump-truck.

It is possible to increase the safety in asphalt paving by introducing either emergency based or fully automated functionality. The largest safety benefit would be achieved if the road traffic could be automated when driving through the construction work. This could possibly remove $33 \%$ of all fatalities in the road worker population. This type of functionality has been demonstrated and could be developed. However, realizing and deploying such a system would need collaboration between several partners.

A high safety benefit could also be achieved by introducing automated braking for trucks. Since this function would work in any type of road work, up to $12 \%$ of all road work fatalities could be expected to be removed. Full automation for trucks would have to be adapted to specific type of tasks and would therefore have a lower safety benefit.

Compactors could be fully automated or equipped with an emergency intervention system. This would lead to considerably increased safety in asphalt paving. However, since compactors are only used in specific type of road works, the safety benefit for the total road worker population would be rather small compared to functions that can be deployed over all type of road works.

It is possible to reduce the number of fatalities by automating tasks that are handled manual by the workers on the ground today. If there are no workers on the ground, no workers can get struck by vehicles or mobile equipment. However, there is a great diversity in the tasks handled by the workers and it would be a major task to automate all the tasks. It would be possible to remove part of the workers by automating parts of their tasks. This would decrease the exposure of workers to safety critical situations.

\section{ACKNOWLEDGMENTS}

The research team would like to acknowledge VINNOVA - Sweden's Innovation Agency and Trafikverket for making this project possible. We would further like to acknowledge AFA Insurance, Infracontrol, NCC, PEAB, SEKO, Skanska and Svevia for their support, incident and accident data reports, and for arranging our construction site visits.

\section{REFERENCES}

Elghamrawy, T. M. (2011). Optimizing work zone pratices for highway construction projects (Doctoral disseration). Retrieved from IDEALS, https://www.ideals.illinois.edu/handle/2142/24344

Friberg, F. (2007). Lugnare arbete på väg (Tech. Rep. No. 2007:26). Retrieved from http://publikationswebbutik.vv.se/upload/2571/2007_26_lugnare_arbete_pa_vag.pdf

Haas, C. T., \& Kim, Y.-S. (2002). Automation in infrastructure construction. Construction Innovation, 2(3), 191-209. doi:10.1191/1471417502ci036oa

Krishnamurthy, B. K., Tserng, H.-P., Schmitt, R. L., Russell, J. S., Bahia, H. U., \& Hanna, A. S. (1998). AutoPave: towards an automated paving system for asphalt pavement compaction operations. Automation in Construction, 8(2), 165-180. doi:10.1016/S0926-5805(98)00060-0- 
Laborers' Health and Safety Fund of North America (1998). Road Construction Hazards Fact Sheet. Retreived on May 12, 2011, from http://www.workzonesafety.org/files/documents/crash_data/factsheet.pdf

Mahoney, K. M., Porter, R. J., Taylor, D. R., Kulakowski, B. T., \& Ullman, G. L. (2006). Design of Construction Work Zones on High-Speed Highways. Retrieved from http://www.nap.edu/catalog.php?record_id=14032

MVA (2006). Roadworker's Safety Focus Groups. Retrieved from http://webarchive.nationalarchives.gov.uk/20100202100434/http://www.highways.gov.uk/knowledge /documents/Roadworkers_Safety_Report_Phase_One_Final.pdf

Pegula, S. (2004). Fatal occupational injuries at road construction sites. Monthly Labor Review, (December), 43-47.

Pegula, S. (2010). Workplace Safety and Health Fatal occupational injuries at road construction sites , 2003 - 07. Monthly Labor Review, (November), 37-40.

Pratt, S. G., Fosbroke, D. E., \& Marsh, S. M. (2001). Building Safer Highway Work Zones : Measures to Prevent Worker Injuries From Vehicles and Equipment. Retrieved from http://www.cdc.gov/niosh/docs/2001-128/pdfs/2001-128.pdf

Schrinner, W., Strauß, M., Lüke, S., \& Komar, M. (2010). Automated Assistance in Roadworks and Congestion : Components installed, working and tested. Retrieved from http://haveiteu.org/LH2Uploads/ItemsContent/24/HAVEit_212154_D51.2_Public.pdf

SEKO (2011). Vägarbetare har inte airbag. Retrieved from http://seko.se/Global/PDF'er/KampanjSankfarten/vagrapport_SEKO_2011.pdf

Skibniewski, B. M., \& Hendrickson, C. (1990). Automation and robotics for road construction and maintenance. Journal of Transportation Engineering, 116(3), 261-271.

Tighe, S., \& McCabe, B. (2006). Evaluation of Work Zone Strategies (Tech. Rep. No. HIIFP-036). Ministry of Transportation, Highway Infrastructure Innovation Funding Program: Ontario. 